\title{
Tele-visões em interfaces contemporâneas
}

\section{Tele-visions in contemporary interfaces}

Suzana Kilpp

Programa de Pós-graduação em Ciências da Comunicação, Universidade do Vale do Rio dos Sinos, São Leopoldo, RS, Brasil ORCID: 0000-0001-7045-6773

<sukilp@unisinos.br>

\section{Como citar este artigo (How to cite this article):}

KILPP, Suzana. Tele-visões em interfaces contemporâneas. Revista Famecos, Porto Alegre, v. 25, n. 3, p. x-xx setembro, outubro, novembro e dezembro de 2018: ID28757. DOI: http://dx.doi.org/10.15448/1980-3729.2018.3.28757.

\section{RESUMO}

O artigo objetiva discutir a dispersão de conteúdos televisivos pela internet e por dispositivos móveis como equivalente à dispersão da televisão nessas mídias. Para tanto analisa, sob a metodologia das molduras, algumas imagens médias de interfaces gráficas nas quais esses conteúdos são acessados online no computador e em dispositivos móveis. Adota como referência teórica principal a fenomenologia bergsoniana, e entende que a questão central para o discernimento gira em torno da compreensão do fenômeno ou coisa chamada interface.

Palavras-chave: Conteúdos televisivos. Telas. Interfaces.

\section{ABSTRACT}

The article aims to discuss the spread of television content over the internet and by mobile devices as equivalent to dispersion of television in these media. Under the methodology of frames, we analyzed some images of graphical interfaces where these contents are accessed online at computer and on mobile devices. We adopt as theoretical reference to phenomenology bergsonian, and we consider that the central issue to the judgment revolves around understanding the phenomenon or something called interface.

Keywords: Television contents. Screens. Interfaces.

\section{Introdução}

O Dicionário Aurélio on-line define interface como um "dispositivo (material e lógico) graças ao qual se efetuam as trocas de informações entre dois sistemas"; como o "limite comum a dois sistemas ou duas unidades que permite troca de informações" etc.

No estudo das televisualidades às vezes atualizamos o verbete aureliano com sentidos mais próximos ao de dispositivo, e às vezes mais próximos ao de limite comum a dois sistemas, mas as duas definições são concernentes à problematização fenomenológica da TV sob o impacto das novas mídias. Assim, contemporâneas, nos termos de Agamben (2009) seriam as interfaces que coexistem no presente, e que, no conjunto, conseguem falar da TV, das outras mídias e da época em que elas estão se realizando. Nessas interfaces coalescem múltiplas temporalidades históricas da TV: sincrônicas, diacrônicas 
ou anacrônicas, elas são sintomáticas de todas as coalescências que habitam o "nosso tempo", temporalidades particularmente críticas (ou dialéticas) quando se manifestam em tantos e diversos espaços (as interfaces) nos quais se presentificam ou atualizam hoje.

As interfaces de que estamos falando têm quase sempre uma faceta mais visível ao usuário/espectador (às vezes chamada de interface gráfica) que é uma parte específica da interface que não deve ser confundida com o todo, pois se trata "apenas" de uma manifestação ou visualização da mesma. Faltam-nos ainda alternativas para designar com maior precisão do que se trata em cada caso, e seguimos falando, no caso de audiovisuais, em telas, mesmo sabedores da insuficiência do termo. Em todo o caso, trata-se daquele espaço da interface em que as narrativas audiovisuais se dão a ver e ouvir desenrolando-se, e que seguiremos convenientemente chamando aqui de tela. Nas telas se disfarçam à percepção todas as demais facetas da interface da mídia, que, no entanto, continuam agindo sobre o que se vê e se ouve.

Para avançar em nossos apontamentos, inicialmente é necessário reconhecer a existência contemporânea dos seguintes principais formatos de telas que importam ao artigo:

- o de monitores de TV;

- o de computadores;

- o de dispositivos móveis.

Nem todos os conteúdos televisivos são ofertados em cada uma das situações, mas em cada um desses formatos pode-se assistir aos mesmos conteúdos televisivos ainda que de modos distintos por conta:

- do tamanho das telas dos suportes;

- dos modos operacionais de cada mídia;

- da mobilidade do suporte e do espectador.

Além disso, muitas vezes se ignora ou negligencia a experiência estética, o repertório cultural e a competência técnica do usuário, que deseja ou precisa navegar ativamente por todas as diferentes interfaces intermediárias que o levam finalmente até o écran de visualização dos conteúdos em um dispositivo fixo ou móvel, no qual, então, se assiste aos mesmos conteúdos em imagens que diferem "apenas" na forma de sua "espacialização".

Frisamos essa apenas aparente banalidade a partir de Bergson (passim), para quem todas as coisas (sic) são um misto de duas tendências: uma que é virtual, da ordem do tempo e da duração da coisa (é a ordem dos conceitos e da memória); e uma que é sua atualização ou realização numa forma, e que é da ordem do espaço e da materialidade da coisa, nos quais a coisa segue durando como potência e devir, aguardando outras suas atualizações. As durações 
no tempo diferem de natureza umas das outras (são coisas verdadeiramente diferentes); as atualizações diferem entre elas apenas em grau (não são outras coisas, apenas outras atualizações da mesma coisa).

Diferenças de grau e diferenças de natureza são as diferenças propostas pelo autor para problematizar os mistos que, a seu ver, são frequentemente "mal colocados", na filosofia e na ciência. Essa problematização atravessa a obra do filósofo, sendo que ela foi sistematizada como método (a intuição, ou método intuitivo) por Deleuze (2004). Bergson (passim) propõe refletir criticamente sobre a especificidade das coisas. Para ele, as coisas podem diferenciar-se umas das outras no espaço/forma (falsas diferenças) ou diferenciar-se de si mesmas no tempo (as verdadeiras diferenças).

A TV que nos interessa aqui é a que dura e devém como mídia. Essa TV que dura é, já, porém, uma atualização da tele-visão. Para facilitar o entendimento, no artigo estaremos chamando de "TV" a consagrada e habituada "mídia" televisão, que é, no entanto, uma das atualizações rizomáticas (realizações na matéria/ forma) de uma virtualidade ou duração que a precede e transcende: a tele-visão. Na medida em que nos fomos aprofundando na fenomenologia bergsoniana, depreendemos que - considerando o que o filósofo propôs quando disse que todas as coisas têm dois modos: o de ser (sua virtualidade ou duração) e o de agir (suas atualizações ou realizações na matéria); e considerando o que o filósofo propôs quando disse que todas as coisas são um misto de duas tendências (a virtual e a atual, relativas ao seu tempo/duração e ao seu espaço/materialização, respectivamente) - a TV pode ser entendida tanto como uma atualização da tele-visão (um dos modos de agir da tele-visão) quanto uma virtualidade ela mesma (o modo de ser de uma espécie da tele-visão que se atualiza e age como TV atualizando-se em outras materialidades nas quais continua, porém, em devir, como televisualidade).

Embora possa parecer que estamos complicando o entendimento do tema sob o viés adotado para sua análise, parece-nos que o estudo da mídia tem sido às vezes bastante simplificadora quando reduz seu entendimento à análise dos conteúdos veiculados por ela, o que é ainda mais problemático e insuficiente sob a convergência dos meios oportunizada pela digitalização de conteúdos de qualquer mídia e por sua dispersão na internet. Uma parte da arqueologia da mídia vem recuperando um pouco esse horizonte quaseabandonado. E uma parte dos estudos de TV vem recuperando as complicadas reflexões de McLuhan e Powers (1993) sobre a mensagem dos meios, sobre as relações entre figura e fundo e sobre as leis da mídia. É nessas duas direções que nos interessam mais a genealogia e a fenomenologia dos meios e os estudos da mensagem do meio, duas visadas que se coadunam mais adequadamente com 
as proposições de Bergson (2005) sobre as espécies e sua evolução criadora, as quais nos permitem avançar no discernimento da mídia TV como uma das espécies resultantes da evolução criadora da tele-visão.

Por isso, dentre tantas visadas possíveis sobre o tema decidimos abordar aqui algumas que tratam de manifestações da TV durante (sua tendência virtual no tempo ou duração) no écran de quaisquer mídias e nas diversas interfaces por elas utilizadas (sua tendência de realização/atualização no espaço, forma, formato ou materialidade).

Reitera-se que, conforme a mídia na qual se queira assistir aos conteúdos passa-se por várias interfaces até se chegar àquela em que os conteúdos veiculados mais se parecem com os veiculados pela televisão. Assim, cada interface pode ser pensada como um dispositivo, e também como o limite entre dois sistemas, porquanto sua diversidade e ubiqüidade liquefazem os sentidos antes sólidos que distinguiam a tela do teor da tela, o qual, no mais das vezes é um teor imagético.

Entretanto, em muitos casos já não se trata do limite de cada sistema, mas do limiar entre eles: aí, poderíamos considerar todas e quaisquer telas de imagens, desde, por exemplo, as da pintura rupestre e as a tinta/óleo em couro, madeira e "telas" etc. até as quais se projetam imagens a laser em prédios e fachadas etc., e as que se gravam em roupas, adesivos, nos corpos etc. Isso é admissível porque, hoje, graças ao memorialismo permitido e estimulado pela tecnologia - que é capaz de presentificar em quaisquer suportes quaisquer imagens produzidas em qualquer suporte e em qualquer tempo histórico - isso torna todos os sistemas contemporâneos (no sentido histórico).

No artigo simplificaremos a discussão, mas reiteramos o enfrentamento necessário do limiar entre os sistemas, limiar já percebido e apontado por Benjamin (2006), um pensador que não conseguimos excluir nunca de nossas considerações sobre a imagem. As telas de cinema, TV, computador e dispositivos móveis são hoje as mais referidas e percebidas como tais; entretanto, todos os suportes, cada um com sua tela, cada uma veiculando uma multiplicidade fantástica de teores imagéticos de qualquer origem multiplicaram-se de tal modo que é quase impossível definir aonde começa e aonde acaba um sistema e qual é o regime visual prevalente num e noutro. Nas interfaces historicamente mais recentes pode-se dizer que quase sempre há televisualidades, porquanto sempre há nelas vestígios, traços ou lembranças da televisão, desde o próprio teor/tema veiculado até os formatos, as estéticas e as linguagens utilizados na construção dos conteúdos audiovisuais nelas veiculados.

Nas interfaces anteriores isso já acontecia, mas de novo optamos por simplificar a discussão no artigo, embora nem sempre seja possível não recorrer 
a elas na análise da tele-visão, que é uma televisualidade que transcende a da mídia TV. Entretanto, isso se torna mais evidente hoje, possivelmente por conta do grande impacto que a TV causou no regime de visibilidade de imagens/ textos, uma vez que as visualidades de TV tiveram um mais rápido e massivo alastramento nos hábitos de recepção e consumo de imagens do Ocidente desde meados do século passado.

Porém, a simples presença de restos, cacos ou rastros da televisão em tais interfaces justifica que as entendamos como telas de TV? Se sim, então, temos de admitir também, por exemplo, que os filmes aos quais assistimos na televisão são cinema, e que a Monalisa de Michelangelo projetada na fachada de um prédio, ou gravada numa camiseta, é pintura... Ou seja, quando se liquefazem os limites físicos e epistemológicos de cada mídia, vivemos em trânsito no limiar de todas, e é fascinante o caos que daí decorre! Vários autores falaram sobre a liquefação da modernidade, e não vamos repeti-los, ainda que estejam subsumidos nos argumentos aqui expostos. Dentre eles, com certeza Bauman (2001) é o que mais impacta nosso viés.

\section{A televisão líquida e a liquefação dos sentidos identitários de TV}

Às vezes parece que tudo que sabíamos até ontem sobre as coisas se desmancharam no ar - ou que se as estejamos liquefazendo. Mas, a nosso ver, apesar do embaralhamento das coisas umas nas outras, elas seguem durando, cada uma delas, ontologicamente, diferenciando-se rizomaticamente de si enquanto atualizações da tele-visão, uma das alternativas que a cada vez mais temos considerado. Mas o mesmo ocorre com as diferenciações de si ou atualizações do cinema, ou da TV etc., dependendo de qual seja a coisa (sic) que estejamos pautando como objeto de pesquisa.

Se quisermos entender a duração televisual, ou seja, o que dura da ontológica mídia TV sob a remediação de conteúdos televisivos nas interfaces hoje existentes nas quais eles são veiculados e moldurados como tais, é precípuo propor que uma interface - qualquer interface - é um território de experiência e significação (uma moldura, portanto) discreto ou discretizado (disfarçado), no qual se ofertam sentidos identitários às coisas para que elas sejam entendidas como sendo tais ou quais coisas. Molduras são quadros ou territórios de significação e experiência dos construtos midiáticos de coisas. Ou seja, as coisas que vemos e ouvimos do conteúdo veiculado pelas mídias são por elas interfaceadas. Elas são construídas, técnica e esteticamente, nos modos peculiares de ser e agir de cada mídia, com a aparência imaginária de uma pessoa, fato, acontecimento, narrativa etc. Nos termos propostos por McLuhan (1993), essa (inter) mediação - desejavelmente discreta em seu modus 
operandi singular - é que é a mensagem do meio. Então, moldurar é um modo de enquadrar e significar o que é enquadrado assim e não de outro jeito: é produzir um ponto de vista sobre as coisas, ou um enquadre (frame) razoável da sitiação de algo num ambiente cultural específico, nos termos de Goffman (1986).

No caso em pauta, trata-se de ofertar sentidos de TV às coisas assim molduradas nas interfaces que elegemos analisar. Entretanto, aí nós novamente nos atrapalhamos com os limiares da televisão, justamente porque seus limites estão se liquefazendo na intensa televisualização que assombra as múltiplas telas e interfaces hoje existentes relacionadas (ou não) à TV. Então, se no artigo interessa-nos entender essa mídia chamada de "televisão" replicada, mimetizada ou lembrada em interfaces de outras mídias, suportes e fluxos, é preciso convocar para a reflexão os estudos sobre a produção, circulação e recepção de conteúdos televisivos; sobre programas, gêneros, discursos e formatos de TV; e sobre o impacto do atual estágio da técnica, da cultura e da economia política sobre a TV, como um todo ou como uma de suas facetas em particular. Também é preciso convocar estudos que revisam teorias e métodos de pesquisa sobre televisão e televisualidades; e estudos relacionados à natureza tecnocultural, discursiva, ética e estética de produtos ou conteúdos televisuais; além dos estudos históricos, arqueológicos e memoriais da televisão, e sua relação com outras mídias, e os estudos de audiovisualidades televisivas.

Na revisão do estado da arte que fizemos encontramos dois textos mais ou menos recentes que se coadunam com tal perspectiva: o de Cannito (2009) e o de Galvão (2006). Nesses textos os autores problematizam o estatuto da TV sob as novas mídias, têm interesse em especificar e entender a ação das diferentes interfaces sobre esse estatuto e pontuam a ingerência da cultura sobre a técnica e vice-versa. Para tanto, ao comparar qualidades próprias do meio TV, da internet e dos dispositivos móveis sob esse viés, eles chamam a atenção para alguns aspectos do fenômeno que precisamos/queremos comentar.

A primeira diz respeito ao fluxo televisual, ao qual temos imputado - a partir de Kilpp (2003) - forte primazia para o discernimento da TV de outras mídias. Sobre isso, Cannito propõe que a criação televisiva

\footnotetext{
implica a criação de fluxos. A grande maioria dos programas de televisão também é organizada como fluxo, uma série de quadros razoavelmente autônomos que se sucedem. A autonomia dos blocos (modularidade) permite que mudanças sejam feitas, quadros retirados, estendidos, tudo em constante diálogo com a audiência (Cannito, 2009, p. 26)
}

Ou seja, a TV, ainda que tenha uma grade de programação razoavelmente sólida, opera na veiculação dos conteúdos sempre atenta à audiência, que 
também está em fluxo. Ainda que os espaços (e tempos) publicitários vendidos para tal ou qual horário imponham algum limite às emissoras, estas podem manipular em tempo real o que estão veiculando com vistas a manter o espectador conectado - o que não prejudica os anunciantes, pois eles também estão sequiosos pela audiência.

Já Galvão refere o impacto da estrutura da programação televisiva sobre toda a produção audiovisual contemporânea:

A estrutura de programação, principalmente de programas que demandam atenção exclusiva para o entendimento de seu conteúdo, somada à tendência de mudar constantemente de canal até encontrar algo que seja interessante, tem impacto direto na estrutura e no desenvolvimento de conteúdo audiovisual na atualidade (Galvão, 2006, p. 11).

Parece-nos que a navegação (mais ou menos aleatória) que fazemos na internet, por exemplo, assemelha-se ao zapping com o qual procuramos alcançar um conteúdo no qual pausar/pousar nossa atenção. Esse conteúdo encontra-se sitiado, de modos bastante similares, em "interfaces de trânsito", nas quais são ofertadas "janelas para o mundo" dentre as quais decidimos a cada passo por qual delas queremos seguir navegando. Mesmo quando se trata, por exemplo, de pinturas, fotografias ou filmes on-line, nos deparamos com essa estrutura "janelada", "canalada", enquadrada, fragmentada e segmentada como a forma de organização e sistematização dos conteúdos colecionados pela rede mundial de computadores para serem consumidos de múltiplas formas pelo usuário/ espectador. Janelas de músicas e de filmes arquivados na rede são exemplos magistrais disso: se os encontra por inteiro, em versões "originais" ou remixadas; e se os encontra em partes das versões "originais" ou remixadas.

Por isso, concordamos com Galvão quando ele diz que

o modelo linear, de conteúdo (integral ou parcial, "original" ou remixado) programado para ser exibido com hora certa e data marcada perde espaço para o conteúdo disponibilizado sob demanda (on-demand), disponível a todo o tempo, a toda hora, de acordo com a vontade do usuário-consumidor (Galvão, 2006, p. 17).

Não acreditamos, porém, que os grandes negócios oportunizados pela modularidade praticada pelas emissoras de TV off-line possam levar, no curto prazo, a substituí-la pela oferta sob demanda, pois esta atrapalha, no atual estágio da técnica, a lógica operacional das empresas associadas ao negócio chamado comunicação. 
Isso se coaduna fortemente com a implicação da audiência nas decisões empresariais atuais, porquanto, por exemplo, como diz Cannito,

\begin{abstract}
a TV também realiza um papel de janela: por meio dela se observa o mundo acontecer. Assim como cada janela pode mostrar um pedaço do mundo específico e diferente, também canais e programas são distintos e mostram narrativas ou jogos diversos. Assim como se pode fechar e abrir a janela, pode-se ligar e desligar a TV. Mas no momento em que se decide olhar por ela, o interesse é de apenas observar, [...] apenas ver (Cannito, 2009, p. 42).
\end{abstract}

Acontece que esse desejo de "apenas ver", sentado na poltrona, o que "se passa" em uma ou noutra janela para o mundo (ainda que, talvez, todos já saibamos tratar-se de ficções) é frustrado, tanto para o espectador quanto para o anunciante, pelos conteúdos acessados on-demand, porque sua lógica "fere" paradoxalmente a inercialidade desejada ao menos por alguns espectadores. Isso ocorre porque a

internet é um meio preponderantemente de arquivo [e o] fluxo então pode acontecer até, por exemplo, o fim da rolagem do vídeo escolhido. Mas depois o fluxo para novamente e a interface exige um novo pedido do usuário (Cannito, 2009, p. 25).

Então, na internet, a TV consegue expandir fantasticamente a difusão dos conteúdos que veicula, mas fica refém das lógicas das plataformas de vídeo, ou seja, das lógicas do acesso a arquivos sob demanda. Nada mal para os conteúdos; mas para as emissoras pode ser um problema, pois assim não se consegue manter nos antigos termos a vinculação entre conteúdo, horário da programação e audiência - o tripé que sustentou até hoje o negócio das TVs off-line.

De outro lado, o espectador-usuário precisa fazer várias coisas diferentes e a mais que antes (off-line) para acessar os conteúdos televisivos via internet. Ou seja, o que antes era colocado como um "mal" da televisão (uma sua insuficiência), agora, minimizado por novas formas de consumo, torna-se, ao menos para alguns consumidores, um outro tipo de "mal": sob a lógica do conteúdo disponibilizado por demanda, o espectador/usuário "precisa fazer alguma coisa para ver". Ele até pode seguir sentado na poltrona, e ele até continua podendo escolher a janela para o mundo por onde o ver. Mas, ele não pode mais reclamar tão facilmente de que alguém está decidindo por ele o que, quando e como verá o que quer ver. Agora que as oportunidades e os modos de agir aumentaram e se diversificaram, ele é "obrigado", em contrapartida, a agir se quiser avançar em alguma nova espécie de fluxo. 
Além disso, perdeu-se aquele sentimento que antes nos irmanava de estar assistindo com todos ao mesmo tempo aos mesmos conteúdos.

Pensamos que tal circunstância é um novo desafio ao discernimento. $E$ não culpamos as novas interfaces por um problema que talvez sequer seja um problema, pois reconhecemos o mérito, apontado também por Cannito, de que cada vez mais,

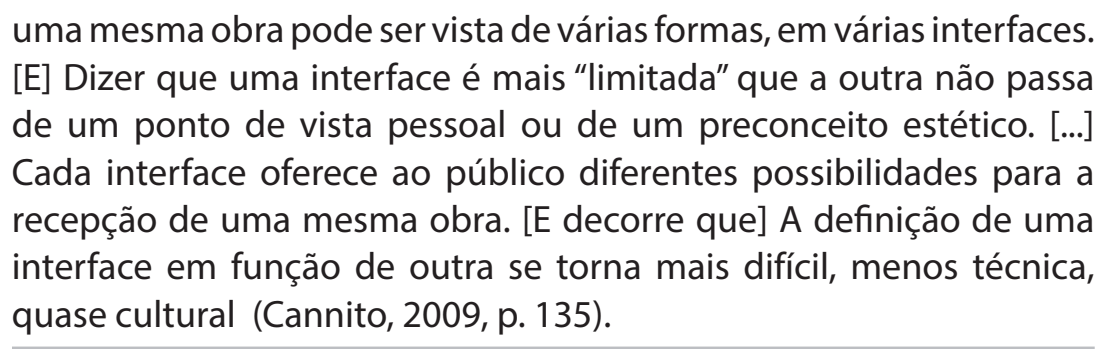

Ou seja, quando o autor, nessa breve citação, parece nos convidar a nos esquivarmos da técnica a favor da cultura, no fundo está nos lembrando da ingerência de uma sobre a outra. Então, quando achamos oportuno pensar a "tela" como "interface" foi porque o segundo termo (cultura) permite flexionar mais expressamente o limite dos "sistemas" e acentuar o caráter "lógico" do dispositivo material, além de (des) acentuar os conteúdos que tendem a fixar nossa atenção no panorama assistido no écran porque é o que é mais útil no presente à ação do espectador: ver o que se passa nessa janela para o mundo.

\section{Sobre as noções de interface}

Temos bastante em conta todos os insights de Manovich (passim) sobre o que o autor chama de cultura do software e de software cultural. Ele traz decisivas contribuições aos estudos das mídias e da cultura sob o impacto dos softwares. Mas até mesmo Manovich escorrega, e há bastante imprecisão ou vagueza em sua noção de interface, ainda que sua "interface cultural" seja uma metáfora bastante produtiva para a reflexão que fazemos.

Por isso, entendemos que seria produtivo à discussão se todo pesquisador que diz estudar essa coisa complexa (ou complicada) dissesse na largada de seus textos o que entende e como usa ou usará o conceito de interface, e em que campo o tem aplicado e sob quais paradigmas. É a esses que lançamos umas perguntas e umas provocações:

e se a imagem do corpo fosse pensada como a interface de todas as imagens?

e se a imagem fosse pensada como a interface da coisa e da coisa percebida? 
e se a coisa fosse a própria interface, qual seria seu virtual e suas atualizações na matéria, seu modo de ser e de agir?

A nosso ver, essas são algumas questões sobre a interface das quais pouco se fala. Mas que poderiam inventar verdadeiros problemas de pesquisa acerca dela. Ou seja, fala-se muito dos modos de agir da interface; mas qual é a tendência da coisa interface, o seu modo virtual de ser? O que é essa coisa que se atualiza nessa e naquela interface?

Manovich (passim) também insiste em sugerir o cinema como interface do audiovisual, embora o cinema, a nosso ver, seja apenas uma das interfaces do audiovisual. Então, o que é mesmo interface para o autor? O que seria para outros autores que temos lido aquilo que eles chamam de audiovisual de interface? Uma virtualidade ou uma sua atualização na matéria? E o que é interface em cada uma dessas situações?

Tomemos por referência algumas imagens médias de interfaces gráficas nas quais eram veiculados conteúdos televisivos na internet no período em que as estivemos monitorando, lembrando que:

estivemos focando a atenção nos seguintes formatos de telas: o de monitores de TV, o de computadores, o de dispositivos móveis;

em cada um desses formatos pode-se assistir aos mesmos conteúdos televisivos ainda que de modos distintos por conta: do tamanho das telas dos suportes, dos modos operacionais de cada mídia, da mobilidade do suporte e do espectador.

Um dos movimentos que fizemos foi comparar a visualização de conteúdos televisivos na internet acessada em computador nos anos de 2007 e 2016, quase dez anos depois. Vejamos os prints das interfaces gráficas (manipuladas) nas figuras abaixo:

\section{- Figura 1 - Conteúdos televisivos acessados em telas de computador}

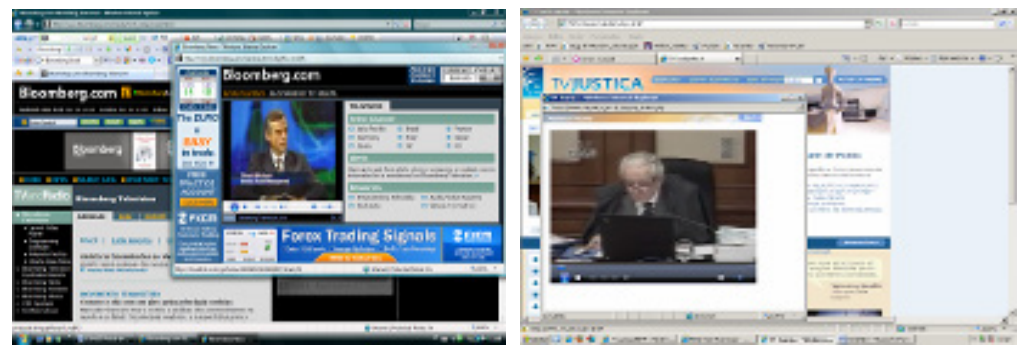




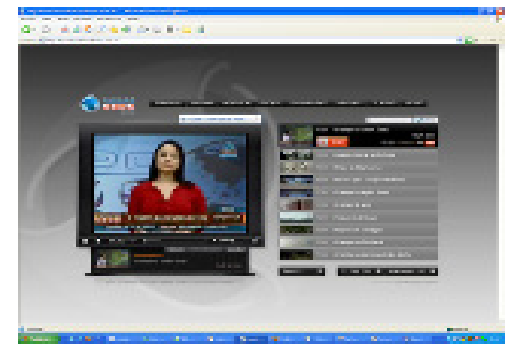

Fonte: elaborado pelo autor (2007)

Figura 2 - Conteúdos televisivos acessados em telas de computador

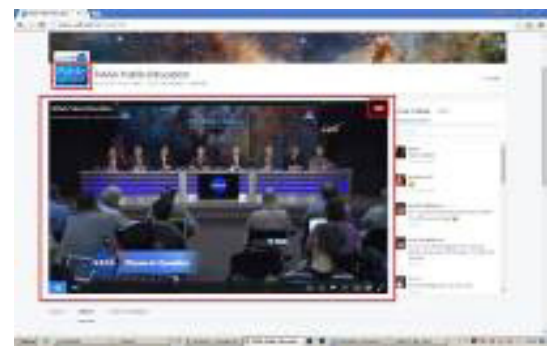

Fonte: elaborado pelo autor (2016)

Nessas interfaces observamos que em 2007 as emissoras analisadas que primeiro ensaiaram sua inserção na internet intentavam preservar mais seus formatos (molduras) off-line: a Bloomberg off-line já tinha um formato gráfico que combinava interfaces televisivas com interfaces praticadas em ambientes on-line; a TV Justiça cravou (sobrepôs/incrustou) a tela de veiculação de conteúdos televisivos na interface gráfica on-line; a TV Record fez o mesmo, mas a tela de exibição de conteúdos televisivos estava nitidamente moldurada por um monitor de TV graficamente desenhado na interface gráfica on-line.

Em 2016, verificamos no design na interface gráfica a prevalência da lógica das interfaces gráficas on-line na molduração de conteúdos televisivos. É verdade que a imagem mostrada (da NASA TV) é de uma emissora que não existia off-line; mas várias outras emissoras a adotaram. Nesses casos, havia construtos identitários da mídia TV nas molduras contornadas em vermelho na figura, construtos esses tipicamente televisivos, construídos off-line e demarcados (moldurados) on-line para que os conteúdos se parecessem aos conteúdos televisivos.

Outro movimento que fizemos foi comparar a visualização de conteúdos televisivos na internet acessada em computador em 2016 com sua visualização, no mesmo ano, em tablets e smartphones. Vejamos os prints de algumas interfaces gráficas (manipuladas) nas figuras a seguir: 
- Figura 3 - Conteúdos televisivos acessados em telas de tablet
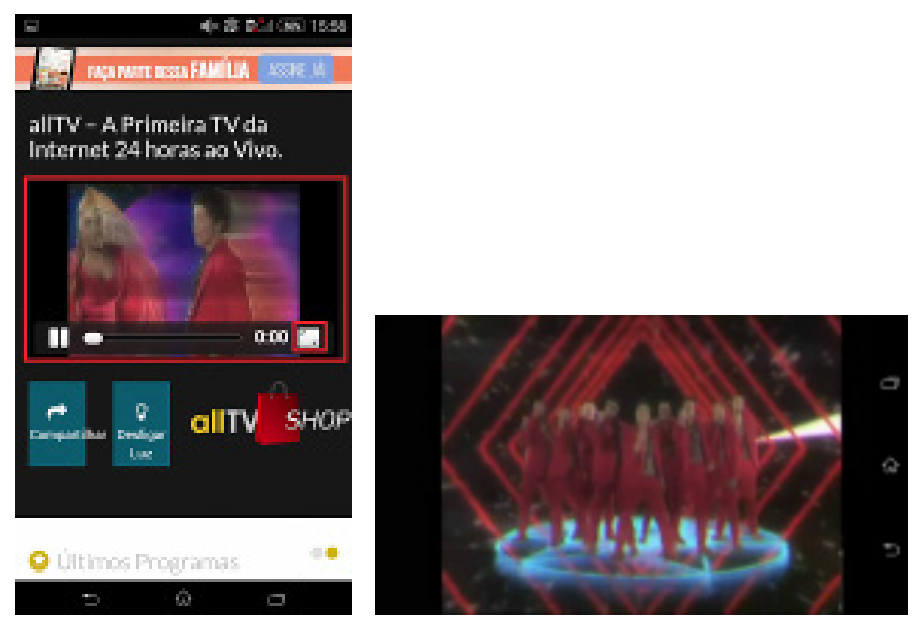

Fonte: elaborado pelo autor (2016)

Figura 4 - Conteúdos televisivos acessados em telas de smatphone

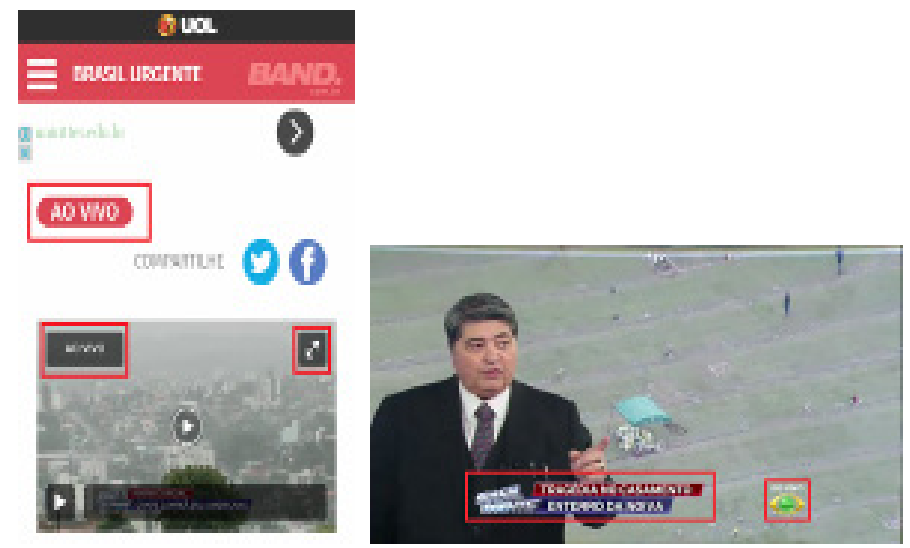

Fonte: elaborado pelo autor (2016)

Assim, verificamos que, sempre, ao se chegar à tela de visualização de conteúdos televisivos, assistia-se efetivamente aos mesmos conteúdos, ainda que em telas de diferentes tamanhos/formatos. Isso acontecia tanto no caso de webTVs (a allTV, no exemplo) quanto no caso de TVs on-line (a Band, no exemplo), sendo que o écran televisual nos dois casos era diferente e próprio da circunstância de se tratarem, no caso, de TVs nativas da internet e de TVs off-line transmitindo na internet: no primeiro caso vê-se a imagem "limpa" de quaisquer sobreposições gráficas, e, na segunda, a manutenção dos grafismos utilizados nas transmissões off-line (contornados por nós em vermelho para destacá-los). 
Nas duas figuras ( 3 e 4), na esquerda inserimos também uma imagem média da interface gráfica que, na navegação, precede a interface gráfica na qual os conteúdos televisivos se dão finalmente a ver. Fica bem claro que ela nada tem a ver com as interfaces gráficas da TV off-line: são tipicamente imagens médias de interfaces de internet criadas para dispositivos móveis (tablet e smartphone, no caso) - outras molduras e moldurações correspondem a outros sentidos enunciados para os conteúdos a serem acessados na navegação em curso.

Dependendo da expertise do usuário, ele chegaria mais ou menos rapidamente a essa interface, sendo que em alguns casos, além da expertise do usuário, os aplicativos das emissoras e os dos dispositivos móveis em questão alterariam substantivamente a experiência do usuário-navegador até que ele alcançasse os conteúdos televisivos inicialmente buscados. Depreendese, portanto, que a experiência de cada indivíduo ou perfil de indivíduo, em cada estágio da técnica, ingere sobre os sentidos dos conteúdos televisivos finalmente acessados.

Nos movimentos que fizemos autenticamos um conjunto de interfaces gráficas que, ao serem acessadas no trânsito, dão a ver as interfaces (discretas ou discretizadas) às quais quisemos dar destaque no artigo, sendo que em cada uma das interfaces gráficas da primeira camada visível havia rastros das segundas, mais profundas, nas quais, a sua vez, quando acessadas por um perfil ou outro do usuário e dos aplicativos, havia rastros de terceiras, quartas, etc., sendo que todas as interfaces gráficas intermediárias deram pistas, mas não conseguiram nunca mostrar "a" interface das televisualidades.

\section{Considerações finais}

Se a interface (como dispositivo material e lógico) das televisualidades relaciona-se ao limite comum a dois sistemas (o da mídia TV off-line e o da mídia TV on-line, tanto na internet quanto nos chamados dispositivos móveis), observamos que esse viés ou perspectiva de análise - que considera apenas e/ou preponderantemente as interfaces gráficas finais de visualização dos conteúdos televisivos - não dá conta do que está em curso ao equiparar a dispersão de conteúdos televisivos pela internet e por dispositivos móveis à dispersão da televisão nessas mídias.

A nosso ver, o que está em curso não é um, mas dois fenômenos: a dispersão (e convergência) da mídia TV, e a dispersão (e convergência) de conteúdos televisivos. $\mathrm{E}$, a partir do que dissemos/mostramos, concluímos que o trânsito, ele mesmo, a experiência, ela mesma, esse confim, ele mesmo, são o que espraiam (dispersam e convergem) as televisualidades em interfaces contemporâneas. 


\section{Referências bibliográficas}

AGAMBEN, Giorgio. O que é o contemporâneo e outros ensaios. Chapecó: Argos, 2009.

BAUMAN, Zygmunt. Modernidade líquida. Rio de Janeiro: Zahar, 2001.

BENJAMIN, Walter. Passagens. Belo Horizonte/UFMG; São Paulo: Imprensa Oficial do Estado da São Paulo, 2006.

BERGSON, Henri. A evolução criadora. São Paulo: Martins Fontes, 2005.

CANNITO, Newton Guimarães. A TV 1.5 - A televisão na era digital. 2009. Tese (Doutorado em Cinema e TV) - Programa de Pós Graduação em Ciências da Comunicação, Universidade de São Paulo, São Paulo, 2009. Disponível em: http://www.teses. usp.br/teses/disponiveis/27/27153/tde-21102010-103237/en.php. Acesso em: 10 set. 2015.

DELEUZE, Gilles. Bergsonismo. São Paulo: Editora 34, 2004.

FLUSSER, Vilém. Filosofia da caixa preta. Ensaios para uma futura filosofia da fotografia. Rio de Janeiro: Relume Dumará, 2002.

GALVÃO, Fabrício Scaffi. Não é TV, é uma nova mídia: o processo migratório do analógico para o digital. In: UNESCOM - Congresso Multidisciplinar de Comunicação para o Desenvolvimento Regional, 2006, São Bernardo do Campo. Unescom - Catedra UNESCO 10 anos. São Bernardo do Campo: Metodista, 2006. v. 1, 9 abr. 2011. Disponível em: http://www.bocc.ubi.pt/pag/galvao-fabricio-nao-tv-uma-novamidia.pdf. Acesso em: 30 nov. 2015.

GOFFMAN, Erving. Frame analysis. An essay on the organization of experience. Boston: Northeastern Press, 1986.

KILPP, Suzana. Ethicidades televisivas. São Leopoldo: UNISINOS, 2003. . Interfaces contemporâneas da TV: paradigmas durantes em telas de dispositivos móveis. In: KILPP, Suzana (Org.). Tecnocultura audiovisual. Temas, metodologias e questões de pesquisa. Porto Alegre: Sulina, 2015.

MANOVICH,Lev. Software takes command.2008. Disponível em: http://softwarestudies. com/softbook/manovich_softbook_11_20_2008.pdf. Acesso em: 10 dez. 2012.

.El lenguaje de los nuevos medios de comunicación: la imagen en la era digital. Buenos Aires: Paidos, 2006.

MCLUHAN, Marshall. POWERS, Bruce. La aldea global. Barcelona: Gedisa, 1993. 
Recebido em: 07/10/2017

Aceito em: 25/01/2018

Dados do autora:

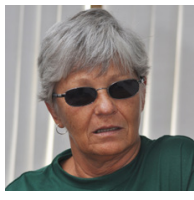

Suzana Kilpp | sukilp@unisinos.br

Universidade do Vale do Rio dos Sinos

Professora e pesquisadora do Programa de Pós-graduação em Ciências da Comunicação

Endereço da autora:

Programa de Pós-graduação em Ciências da Comunicação, Universidade do Vale do Rio dos Sinos

Av. Unisinos, 950. Bairro Cristo Rei

93.022-750, São Leopoldo, RS, Brasil

Este artigo é licenciado sob forma de uma licença Creative Commons Atribuição 4.0 Internacional (CC-BY). 